University of Wollongong

Research Online

Faculty of Social Sciences - Papers (Archive) Faculty of Arts, Social Sciences \& Humanities

2015

The relationship between expressed emotion and wellbeing for families and carers of a relative with Borderline Personality Disorder

Rachel C. Bailey

University of Wollongong, rbailey@uow.edu.au

Brin F. S Grenyer

University of Wollongong, grenyer@uow.edu.au

Follow this and additional works at: https://ro.uow.edu.au/sspapers

Part of the Education Commons, and the Social and Behavioral Sciences Commons

Research Online is the open access institutional repository for the University of Wollongong. For further information contact the UOW Library: research-pubs@uow.edu.au 


\title{
The relationship between expressed emotion and wellbeing for families and carers of a relative with Borderline Personality Disorder
}

\author{
Abstract \\ Background: Previous research has found that family environments high in expressed emotion, in \\ particular emotional overinvolvement, are beneficial to the clinical outcome of patients with Borderline \\ Personality Disorder (BPD). Aim: This study aims to investigate the relationship between expressed \\ emotion, carer burden and carer wellbeing. Method: A total of 280 carers of a relative with BPD were \\ administered the McLean Screening Instrument for BPD - Carer Version, The Family Questionnaire, Burden \\ Assessment Scale and Mental Health Inventory. Results: Carers reported family environments high in \\ expressed emotion, particularly criticism ( $82.9 \%$ of carers) and emotional overinvolvement $(69.6 \%)$. \\ Elevated emotional overinvolvement was correlated with higher burden and mental health problems. \\ Conclusions: Elevated criticism and emotional overinvolvement in family environments represent a \\ dynamic involving high conflict, anxious concern, overprotection and emotional closeness. The findings \\ suggest that carers may benefit from intervention and support options considering the challenged \\ interpersonal dynamic, burden and impaired carer wellbeing reported in this study.
}

\section{Keywords}

wellbeing, emotion, personality, expressed, borderline, between, relationship, relative, carers, families, disorder

\section{Disciplines}

Education | Social and Behavioral Sciences

\section{Publication Details}

Bailey, R. C. \& Grenyer, B. F. S. (2015). The relationship between expressed emotion and wellbeing for families and carers of a relative with Borderline Personality Disorder. Personality and Mental Health: multidisciplinary studies from personality dysfunction to criminal behaviour, 9 (1), 21-32. 
The relationship between expressed emotion and wellbeing for families and carers of a relative with Borderline Personality Disorder

Running Title: EXPRESSED EMOTION IN BORDERLINE DISORDER 


\begin{abstract}
BACKGROUND: Previous research has found that family environments high in expressed emotion, in particular emotional overinvolvement, are beneficial to the clinical outcome of patients with Borderline Personality Disorder (BPD).
\end{abstract}

AIM: To investigate the relationship between expressed emotion, carer burden and carer wellbeing.

METHOD: 280 carers of a relative with BPD were administered the McLean Screening Instrument for BPD - Carer Version, The Family Questionnaire, Burden Assessment Scale and Mental Health Inventory.

RESULTS: Carers reported family environments high in expressed emotion, particularly criticism (82.9\% of carers) and emotional overinvolvement (69.6\%). Elevated emotional overinvolvement was correlated with higher burden and mental health problems.

CONCLUSIONS: Elevated criticism and emotional overinvolvement in family environments represent a dynamic involving high conflict, anxious concern, overprotection and emotional closeness. The findings suggest that carers may benefit from intervention and support options considering the challenged interpersonal dynamic, burden and impaired carer wellbeing reported in this study.

Keywords: Carer, Borderline Personality Disorder, expressed emotion, emotional overinvolvement. 


\section{INTRODUCTION}

The family environment has been a controversial and sensitive topic for people with Borderline Personality Disorder (BPD) and their carers. Early research identified associations of inadequate parenting and abuse with the development of BPD (e.g., Herman, Perry, \& van der Kolk, 1989; Landecker, 1992; Masterson \& Rinsley, 1975; Soloff \& Millward, 1983; Zanarini, Gunderson, Marino, Schwartz, \& Frankenburg, 1989). Early trauma has been suggested to be an important determinant in BPD development (Herman et al., 1989; Herman \& van der Kolk, 1987). Recent findings now suggest that factors other than early childhood experience may also contribute to the development of BPD in a biopsychosocial model (Leichsenring, Leibing, Kruse, New, \& Leweke, 2011). These include genetic (Distel et al., 2008), biological (Herpertz et al., 2001), and social-cognitive factors (King-Casas et al., 2008), and therefore that BPD is not simply complex Post Traumatic Stress Disorder (Lewis \& Grenyer, 2009).

Current guidelines recommend that clinicians work with families and carers of people with BPD (National Health and Medical Research Council, 2012; National Institute for Health and Clinical Excellence, 2009; Project Air Strategy for Personality Disorders, 2012) and research has begun to emerge on determining family environments that are most beneficial to the clinical outcome of the patient. The family environment has been found to have important implications for the clinical outcome of patients with a mental illness. In particular, there has been extensive research into the impact of expressed emotion (a measure of family environment involving behaviours and attitudes of hostility, criticism and emotional overinvolvement). Research has found that family environments with high expressed emotion are deleterious to the clinical outcome of patients with schizophrenia (Bebbington \& Kuipers, 1994), depression (Hooley, Orley, \& Teasdale, 1986), bipolar (Miklowitz, Goldstein, Nuechterlein, Snyder, \& Mintz, 1988) and eating disorders (Butzlaff \& Hooley, 1998). Thus, 
family environments characterised by elevated expressed emotion have been found to be unhelpful to the recovery of patients with these disorders.

The impact of expressed emotion on the clinical outcome of patients with BPD has also been researched. Hooley and Hoffman (1999) explored the association between carer expressed emotion and patient relapse over one year. Contrary to research with other mental health disorders, criticism and hostility did not predict clinical outcome at follow-up for patients with BPD. However, emotional overinvolvement was associated with better clinical outcomes for patients with BPD, even when initial symptom severity was statistically controlled. The authors speculated that the nature of emotional overinvolvement (the expression of overprotection, anxious concern and extreme emotional closeness) might be experienced as validating and therefore potentially helpful towards recovery for the BPD patient (Hoffman \& Hooley, 1998; Hooley \& Hoffman, 1999).

Further research was then undertaken to explore neurological differences. Hooley and colleagues (2010) found that verbal comments expressing emotional overinvolvement cause neurological activation of the left superior frontal gyrus for patients with BPD compared to patients with dysthymia and healthy controls. This area of the brain has been associated with the processing of reward, approach-related or engaging stimuli (Pizzagalli, Sherwood, Henriques, \& Davidson, 2005). Interestingly, the neurological difference between groups was not reflected in self-report findings; patients with BPD rated the valence of the comments as equally negative as the patients with dysthymia and healthy controls (Hooley et al., 2010). Therefore, family environments high in emotional overinvolvement might be experienced as rewarding and validating to people with BPD on a neurological level.

Previous research has established the unexpected benefits of family environments high in emotional overinvolvement on the outcome of patients with BPD. Although emotional overinvolvement is probably a reasonable response to the distress of a loved one with BPD,, 
the impact of a family environment characterized by anxious concern, overprotection and extreme emotional closeness on the wellbeing of the carer remains unknown. Previous research has identified an association between elevated emotional overinvolvement, higher distress and reduced wellbeing for carers of persons with other disorders such as schizophrenia (Boye et al., 1998; Carrà, Cazzullo, \& Clerici, 2012; Jeppesen et al., 2000) and intellectual disabilities (Dossetor, Nicol, Stretch, \& Rajkhowa, 1994). Thus, the present study aimed to investigate the relationship between expressed emotion, burden and wellbeing in carers of persons with BPD.

\section{METHODS}

\section{Ethical Approval and Study Design}

Participants gave explicit consent to participate following Institutional Board approval of the study. Carers were invited to complete the survey through calls in community forums including carer events, newsletters, blogs and websites. Therefore, carers who participated in the research were likely to be actively engaged in seeking support, education and information; suggesting that they were aware of the issues involved in being a carer of a relative with BPD.

For the purpose of the research, 'relative' was defined as a person with BPD who could be biologically (e.g. parent, child, sibling) or non-biologically (e.g. partner, significant other) related to the carer. 'Carer/caregiving' was defined as consisting of regular interactions with the relative involving tasks promoting wellbeing and recovery, which could include simply being in a supportive relationship. To gain access to the survey carers were required to endorse the question "Do you have a relative (including biological - such as parent or sibling, or non-biological - including significant other or friend) with a personality disorder?” Previous research has reported that many carers are unaware of the specific diagnosis of BPD (Hoffman, Buteau, Hooley, Fruzzetti, \& Bruce, 2003). Therefore, in a 
conservative effort to ensure that the carers were appropriate to the research they were also required to rate their relative on the McLean Screening Instrument for BPD - Carer Version and endorse at least 7 items to be included in the study (MSI-BPD-C, described below; Zanarini et al., 2003).

Participants

A total of 532 carers consented to the survey. 194 carers were excluded due to: immediately reporting that they do not have a relative with a personality disorder ( $n=65)$; not completing any questions $(n=129)$; or scored less than 7 on the MSI-BPD-C $(n=58)$. Therefore a total of 280 carers were included in the study. Table 1 outlines the characteristics of the carer, and Table 2 the characteristics of the relative with BPD.

PUT TABLE 1 AND TABLE 2 ABOUT HERE

\section{Measures}

McLean Screening Instrument for Borderline Personality Disorder - Carer Version (MSI-BPD-C). The MSI-BPD (Zanarini et al., 2003) is a 10 item measure of BPD symptoms, used as a screening instrument. The endorsement of 7 or more items has shown good sensitivity and specificity for the Diagnostic and Statistical Manual of Mental Disorders (DSM-5; American Psychiatric Association, 2013) diagnosis of BPD (Zanarini et al., 2003). The present sample had a mean score of $8.70(\mathrm{~N}=280, \mathrm{SD}=1.04)$. The MSI-BPD has been adapted in previous research for carers to endorse observed symptoms of the relative with BPD (Goodman et al., 2011).

The Family Questionnaire (TFQ). The TFQ (Wiedemann, Rayki, Feinstein, \& Hahlweg, 2002) is a 20 item measure of carer expressed emotion in the family environment. The TFQ includes 10 items for criticism and 10 items for emotional overinvolvement, where higher scores represent higher levels of criticism and emotional overinvolvement. TFQ has been shown to correlate well with the Camberwell Family Interview which has often been 
used in the measurement of expressed emotion (Wiedemann et al., 2002). Both criticism $(\alpha=0.86, N=257)$ and emotional overinvolvement $(\alpha=0.80, N=256)$ subscales showed strong internal consistency.

Burden Assessment Scale (BAS). The BAS (Reinhard, Gubman, Horwitz, \& Minsky, 1994) is a 19 item measure of two domains of burden; objective and subjective. Objective burden relates to the self-reported behavioural effects of caregiving (such as changes in work, social and family life), whereas subjective burden involves feelings, attitudes and emotions expressed about the caregiving role (such as embarrassment and guilt; Platt, 1985; Reinhard et al., 1994). Higher scores on this measure represent greater experiences of objective and subjective burden. The BAS showed strong internal consistency $(\alpha=0.87, \mathrm{~N}=264)$.

Mental Health Inventory - 5 (MHI-5). The MHI-5 (Cuijpers, Smits, Donker, ten Have, \& de Graaf, 2009) is a 5 item scale with excellent validity for measuring symptoms consistent with depression and anxiety, and has a long history of use in large scale health studies. The MHI-5 total score was linear transformed to a scale of 0 to 100, consistent with previous research (e.g., Cuijpers et al., 2009; Rumpf, Meyer, Hapke, \& John, 2001; Theunissen, Jansen, \& van Gestel, 2011), where higher scores represent better mental health. The MHI-5 showed strong internal consistency $(\alpha=0.85, \mathrm{~N}=240)$.

Qualitative Data. 219 of the 280 included carers responded to the question "as a carer, what is your experience of caring for your relative (what impact has it had on you, your life and relationships)?” This additional qualitative information was sought to supplement the quantitative data and provide further insight.

\section{RESULTS}

201 (71.8\%) carers returned complete surveys and 78 carers returned surveys with some missing data. Responses with missing data were not significantly different to participants with full data on demographics including carer gender, $\chi^{2}(1)=0.18, p=0.67$, 
relative with BPD age, $t(157.14)=-0.68, p=0.50$ (equal variances not assumed), relative gender, $\chi^{2}(1)=1.73, p=0.19$, the length of the caregiving relationship, $t(258)=-1.06, p=0.29$ or whether they were biologically or non-biologically related to the person with BPD, $\chi^{2}(1)=1.67, p=0.20$. Carer age was significantly older for those with some missing data $(\mathrm{M}=49.49, \mathrm{SD}=12.30)$ compared to those with full data $(\mathrm{M}=46.04, \mathrm{SD}=11.15), t(277)=2.24$, $p=0.03$, however the effect size was small, $d=0.27$. All available data were included in analyses, meaning sample sizes were different depending on the missing data as shown in Table 3. Variables were significantly skewed violating assumptions of normality; therefore non-parametric tests of association are reported. Table 4 provides a Kendall tau-b two-tailed statistic correlation matrix of the variables.

Are scores on the variables different when considering heritability?

To investigate whether the findings were the result of heritability, the responses of biologically and non-biologically related carers were compared (see Table 5 for means). Biologically related carers were not significantly different to non-biologically related carers on TFQ criticism, $t(255)=-0.22, p=0.83$, TFQ emotional overinvolvement, $t(254)=-1.50$, $p=0.14$, and the MHI-5, $t(238)=1.64, p=0.10$. Non-biologically related carers scored significantly higher on the Burden Assessment Scale (BAS) than biologically related carers, $t(259.96)=2.20, p=0.03$ (equal variances not assumed), however the effect size was small, $d=0.27$. Further, parents were not significantly different to partners or spouses on TFQ criticism, $t(187)=-1.00, p=0.32$, TFQ emotional overinvolvement, $t(187)=-1.12, p=0.26$, the MHI-5, $t(177)=1.63, p=0.11$ or the BAS, $t(193)=-1.56, p=0.12$.

PUT TABLES 3 AND 4 ABOUT HERE

Severity of expressed emotion, burden and mental health symptoms 
In relation to expressed emotion, carers reported a mean score of 31.12 on the TFQ subscale of criticism and 30.32 for emotional overinvolvement. Previous research has suggested that mean scores greater than 23 are considered elevated for criticism, and greater than 27 for emotional overinvolvement (Wiedemann et al., 2002). Therefore, on average carers reported elevated criticism and emotional overinvolvement within the family environment. TFQ emotional overinvolvement was not significantly correlated with carer age, $\tau=-0.02, \mathrm{p}=0.62, \mathrm{n}=255$ or length of the caregiving relationship, $\tau=-0.07, \mathrm{p}=0.12, \mathrm{n}=243$. However, TFQ emotional overinvolvement was negatively correlated with age of the relative with BPD, $\tau=-0.14, \mathrm{p}=0.001, \mathrm{n}=256$ using the Kendall tau-b two-tailed statistic. Further, TFQ criticism was negatively correlated with carer age, $\tau=-0.10, p=0.02, n=256$ and positively correlated with the length of the caregiving relationship $\tau=0.09, \mathrm{p}=0.04, \mathrm{n}=243$ and relative age, $\tau=0.10, p=0.03, n=256$ using the Kendall tau-b two-tailed statistic. Thus, emotional overinvolvement was higher for carers of a younger person with BPD. Higher levels of criticism were also associated to younger age of the carer, longer duration of the caregiving relationship and older age of the relative with BPD.

Carers reported an average of 56.67 on the Burden Assessment Scale (BAS), where higher scores represent greater experiences of burden. Previous research with the same measure has reported a mean of $38.54(\mathrm{~N}=135, \mathrm{SD}=13.27)$ for carers of psychiatric inpatients with mood, substance, anxiety and psychotic disorders (Page, Hooke, O'Brien, \& de Felice, 2006). Therefore, carers of a relative with BPD endorsed levels of burden over one standard deviation higher than carers of patients with other mental illnesses. This difference was significant, $t(217.74)=13.90, p=0.00$ (equal variances not assumed), with a very large effect size, $d=1.88$. The BAS was not significantly correlated with carer age, $\tau=-0.06, \mathrm{p}=0.18$, $\mathrm{n}=264$, or the length of the caregiving relationship, $\tau=-0.03, \mathrm{p}=0.45, \mathrm{n}=247$, using the Kendall tau-b two-tailed statistic. However, the BAS was negatively correlated with the age of the 
relative, $\tau=-0.14, \mathrm{p}=0.001, \mathrm{n}=263$. Therefore, burden was significantly higher for carers of a younger person with BPD.

Finally, carers reported an average score of 55.82 on the MHI-5, where higher scores represent better mental health. Previous research has suggested that scores less than 65 represent symptoms consistent with mood or anxiety disorders (Rumpf et al., 2001). 64.2\% of participants scored 65 or less in the present sample. Therefore the majority of carers of people with BPD endorsed mental health problems consistent with clinical mood or anxiety disorders. The MHI-5 was not significantly correlated with carer age, $\tau=0.05, p=0.27, n=239$, relative age, $\tau=-0.02, p=0.64, n=239$, or the length of the caregiving relationship, $\tau=0.05$, $\mathrm{p}=0.26, \mathrm{n}=230$, using the Kendall tau-b two-tailed statistic. The mean, median, standard deviation and range of the TFQ, BAS and MHI-5 are reported in Table 3.

PUT TABLE 5 ABOUT HERE

Is emotional overinvolvement related to carer burden and mental health?

TFQ emotional overinvolvement correlated positively with the Burden Assessment Scale (BAS), $\tau=0.49, \mathrm{p}=0.00, \mathrm{n}=249$, and negatively correlated with the MHI-5 (where higher scores represent better mental health), $\tau=-0.32$, $\mathrm{p}=0.00, \mathrm{n}=237$ using the Kendall tau-b twotailed statistic. Therefore, higher emotional overinvolvement was correlated with greater burden and reduced carer mental health. A mother provided a qualitative example of emotional overinvolvement, "I will do anything to help her. I read, research and will fight to get her the best treatment. But I find that her issues become all I can think about sometimes. It's hard to find a good balance of my needs and helping her [to] navigate life."

Previous research has suggested that TFQ scores greater than 27 are high and scores of 27 or less are low for emotional overinvolvement (Wiedemann et al., 2002). In the present sample, 61 participants (21.8\%) endorsed low emotional overinvolvement. Carers who 
endorsed low emotional overinvolvement scored a mean of $46.43(\mathrm{SD}=10.50$, median=45.5, range $=19-66$ ) on the BAS, which is within the same standard deviation as previous research with carers of psychiatric inpatients with mood, substance, anxiety and psychotic disorders ( $N=135, M=38.54, S D=13.27$; Page et al., 2006). However, carers who reported high emotional overinvolvement (69.6\%) scored a mean of $59.82(\mathrm{SD}=7.97$, median=61, range $=35-75$ ) on the BAS, which is more than one standard deviation higher than previous research (Page et al., 2006). The difference of BAS scores for low and high emotional overinvolvement groups was significant, $t(77.95)=-8.96, p=0.00$, with a very large effect size, $d=2.03$ (equal variances not assumed).

Carers who endorsed high emotional overinvolvement scored a mean of 51.60 ( $S D=20.43$, median=52, range $=0-92)$ on the MHI-5, where higher scores represent better mental health. Scores of less than 65 on the MHI-5 have been suggested to represent the experience of symptoms consistent with clinical mood and anxiety disorders (Rumpf et al., 2001), thus carers high in emotional overinvolvement report experiencing symptoms consistent with clinical anxiety and depression. In contrast, carers who scored low emotional overinvolvement reported a mean of $69.50(\mathrm{SD}=19.05$, median $=72$, range $=20-96)$ on the MHI-5, representing sub-clinical mental health difficulties (Rumpf et al., 2001). The difference between MHI-5 scores for high and low emotional overinvolvement groups was significant, $t(235)=-5.82, p=0.00$, with a large effect size, $d=0.76$. These results show that family environments high in emotional overinvolvement are correlated with increased experience of burden and mental health problems for the carer.

Is criticism related to carer burden and mental health?

In the present sample, 232 participants (82.9\%) endorsed high levels of criticism on the TFQ (mean score greater than 23; Wiedemann et al., 2002). Kendall's tau-b two-tailed 
showed that TFQ criticism scores were positively correlated with Burden Assessment Scale (BAS), $\tau=0.29, p=0.00, n=251$, TFQ emotional overinvolvement, $\tau=0.31, p=0.00, n=253$, and negatively correlated with MHI-5 (where higher scores represent better mental health), $\tau=-$ $0.15, p=0.00, n=237$. Therefore, higher levels of criticism were associated to greater burden and emotional overinvolvement, and reduced carer mental health scores. An adult daughter provided a qualitative example of criticism, stating that the most challenging aspect of caregiving was "not having a mother, but a 62 year old child”, whereas a partner stated "dealing with the 180 degree mood swings. Sometimes she enjoys just keeping me on my toes I'm sure of it!"

\section{DISCUSSION}

Previous research has demonstrated that family environments high in expressed emotion, particularly emotional overinvolvement, are paradoxically beneficial to clinical outcome and activate areas of the brain involved in reward processing for patients with BPD (Hooley et al., 2010; Hooley \& Hoffman, 1999). However, the present study found that family environments characterised by high emotional overinvolvement are associated with impaired wellbeing and higher burden for carers of persons with BPD. This finding is consistent with previous research with carers of persons with other disorders (e.g., Boye et al., 1998; Dossetor et al., 1994; Jeppesen et al., 2000) and did not change when considering whether the carer was biologically or non-biologically related to the person with BPD.

BPD is a disorder of interpersonal functioning (Hoffman \& Hooley, 1998) and is defined by the DSM-5 as involving pervasive instability in interpersonal relationships (American Psychiatric Association, 2013). Thus, the burden associated with caregiving for a relative with mental illness may be amplified by the interpersonal nature of BPD. For instance, previous research has identified a conflict between involvement and independence for patients with BPD when reflecting on the relationship with their parents (Gunderson \& 
Lyoo, 1997). The present findings also correspond to Hooley and Hoffman's suggestion that carers may "suffer along with the patient” (1999, p. 1561) and previous findings of interpersonal strain when caring for a person with personality disorder (Bailey \& Grenyer, 2014). The findings are also supported by previous qualitative research describing conflicting emotions of love and anger while caring for a daughter with BPD (Giffin, 2008). A wife qualitatively described the experience of closeness and conflict in the present study as follows "I find myself crying on my own a lot and I feel anxious that, at 45, I am now facing deep regrets about my choice to stay with him after meeting him when I was $17 . .$. my husband has a lot of insight (when he's not 'on one') and strives to be a better person, he's charming, hilarious, very clever... So I love him and I hate him and that is very challenging for me.”

The challenging nature of the caregiving relationship, involving both emotional closeness and conflict, may also be paralleled in the therapeutic relationship. Clinicians express greater negative valence when discussing their responses to patients with BPD compared to Major Depressive Disorder (Bourke \& Grenyer, 2010). The push-pull interpersonal dynamic may contribute to this experience (Bourke \& Grenyer, 2013). Considering that this interpersonal strain may be challenging for trained clinicians to hold, it is likely that many carers are also struggling with a similar push-pull dynamic (characterised by both conflict and emotional closeness), as the data presented here suggests.

Interestingly, the present study found that biological versus non-biological relations did not influence the endorsement of criticism, emotional overinvolvement and mental health problems. This finding is of importance, as previous research has focussed primarily on parents of a person with BPD (Bailey \& Grenyer, 2013; Goodman et al., 2011). It has been suggested that people with BPD select non-biological carers or partners who will continue interpersonal patterns enacted by biological relatives (Hoffman \& Hooley, 1998). However, 
this result could be conversely related to the experience of caregiving. For instance, the challenged interpersonal dynamic, impact on carer wellbeing and the witness of distressing and disturbing behaviours of a loved one with BPD may contribute to the development of secondary traumatisation regardless of biological relatedness. In the present study a wife described secondary traumatisation of impulsive anger as a "battle between love and fear. Loving too much to let go or let him down, while feeling scared in my own home for that same person I love so much and who should be the one I feel most safe with”. A mother commented on the secondary traumatisation of self harm, “The most challenging aspects have been trying to look at the devastation my daughter [has] done to herself, e.g. cutting, overdoses, hanging, running out in front of a bus and a few cars, attempting to throw herself off a motorway bridge, setting herself on fire, her sisters cutting her from a rope."

The present findings raise the question of whether clinicians should intervene when presented with carers of a relative with BPD experiencing family environments elevated in emotional overinvolvement. People with BPD experience a disturbed sense of self including feelings of emptiness, rejection sensitivity and intense fears of abandonment (American Psychiatric Association, 2013). Therefore it is plausible that carer's expressions of anxious concern, overprotection and extreme emotional closeness may be experienced as reassuring and validating to the person with BPD (Hoffman \& Hooley, 1998; Hooley \& Hoffman, 1999). However, the present study found that a family environment characterised by emotional overinvolvement is also associated with impaired carer wellbeing. Therefore, the present results suggest important clinical implications; emotional overinvolvement has been demonstrated as beneficial to BPD patient outcome, yet also associated with impairment in carer wellbeing including increased experience of burden and carer mental health problems.

The clinical implications of these findings reinforce the importance of collaborative treatment for both the patient (to develop and integrate a stronger sense of self, diminish 
abandonment fears, increase rejection tolerance and emotion regulation capacity) and the carer (to balance healthy separation and facilitate care for self along with caring for the relative with BPD) where possible. However, where the person with BPD is not willing or unable to seek treatment, it is likely that carers may still benefit from support options to improve wellbeing and decrease burden and isolation. It is suggested that carers of a person with BPD might be receptive to the approach of effectively validating their loved one whilst maintaining healthy separation and boundaries. A mother commented; " my husband and I have made mistakes but not with any bad intentions, yet we keep hearing that BPD is due to trauma and abuse caused in early childhood. This paints all carers of someone with BPD as being somehow 'bad' and yet the parents that I know love their daughters and are desperate for some sort of help and understanding of the illness. We want to know how to help yet at the same time keep our sanity by setting suitable boundaries.”

The present study is important in increasing understanding of the issues involved in caring for a relative with BPD, however several limitations must also be considered when interpreting these results. This study was correlational in nature, therefore relationships between variables are difficult to interpret in terms of which were primary or secondary effects. Further, it is possible that a common variable may explain the association between expressed emotion and carer wellbeing. The study was advertised on carer forums, thus involved carers that may have been more inclined to visit such forums and self-select to participate in the research. Further, although the study used a screening instrument in an attempt to ensure that the included carers were appropriate to the research, the study is limited in not confirming the diagnosis of BPD with a comprehensive assessment of the carer's relative. The study also did not invite participation from the relative with BPD, therefore all results are based on cross-sectional carer reports. The study did not include a sufficient sample size of siblings and children of people with BPD to allow statistical 
comparison of the experience of burden for these groups compared to parents and partners. We did not collect data on ethnicity so how this may moderate the findings reported here is unknown. Future research may benefit from addressing these issues. In sum, it is likely that a collaborative treatment approach, where possible, may be most beneficial to the outcome for both carer and relative with BPD. However, even where a collaborative treatment approach is not possible, it remains that carers of persons with BPD may benefit from intervention and support options considering the challenged interpersonal dynamic, burden and impaired carer wellbeing reported in this study. 


\section{TABLES}

\begin{tabular}{|c|c|c|}
\hline \multicolumn{3}{|c|}{ Carer } \\
\hline Age (279) & Mean (range) & 47.00 years $(16-75)$ \\
\hline & Median & 47.00 years \\
\hline \multirow[t]{2}{*}{ Length of caregiving relationship (260) } & Mean (range) & 12.40 years $(0-59)$ \\
\hline & Median & 10.00 years \\
\hline \multirow[t]{2}{*}{ Gender } & Male (81) & $28.9 \%$ \\
\hline & Female (199) & $71.1 \%$ \\
\hline \multirow[t]{4}{*}{ Employment } & Full-time (145) & $51.8 \%$ \\
\hline & Part-time (63) & $22.5 \%$ \\
\hline & Unemployed (68) & $24.3 \%$ \\
\hline & Did not state (4) & $1.4 \%$ \\
\hline \multirow[t]{6}{*}{ Relationship to the relative with BPD } & Mother (99) & $35.4 \%$ \\
\hline & Father (14) & $5.0 \%$ \\
\hline & Child (41) & $14.6 \%$ \\
\hline & Sibling (10) & $3.6 \%$ \\
\hline & Partner/Spouse (92) & $32.9 \%$ \\
\hline & Significant Other (24) & $8.6 \%$ \\
\hline \multirow{3}{*}{$\begin{array}{l}\text { Do you provide most of the care for your } \\
\text { relative? }\end{array}$} & Yes (155) & $55.4 \%$ \\
\hline & No (124) & $44.3 \%$ \\
\hline & Did not state (1) & $0.4 \%$ \\
\hline \multirow{3}{*}{$\begin{array}{l}\text { Has a mental health professional explained } \\
\text { the diagnosis to you? }\end{array}$} & Yes (175) & $62.5 \%$ \\
\hline & No (102) & $36.4 \%$ \\
\hline & Did not state (3) & $1.1 \%$ \\
\hline \multirow{2}{*}{$\begin{array}{l}\text { Have you ever sought any support options } \\
\text { (support groups, long/short term therapy, } \\
\text { internet support, education)? }\end{array}$} & Yes (251) & $90.0 \%$ \\
\hline & No (28) & $10.0 \%$ \\
\hline \multirow{4}{*}{$\begin{array}{l}\text { Have you been satisfied with the support } \\
\text { options you have been offered? }\end{array}$} & Yes (126) & $45.0 \%$ \\
\hline & No (108) & $38.6 \%$ \\
\hline & N/A (36) & $12.9 \%$ \\
\hline & Did not state (10) & $3.6 \%$ \\
\hline
\end{tabular}

Table 1. Demographic characteristics of the carers. Numbers in parentheses indicate sample size. 


\section{Relative with Borderline Personality Disorder}

\begin{tabular}{lll}
\hline Age (279) & Mean (range) & 40.23 years (12-90) \\
Gender & Median & 36.00 years \\
& Male (73) & $26.1 \%$ \\
Employment & Female (207) & $73.9 \%$ \\
& Full-time (60) & $21.4 \%$ \\
& Part-time (41) & $14.6 \%$ \\
& Unemployed (175) & $62.5 \%$ \\
Hospitalisations (to carers knowledge) in & Mean (range) & $1.4 \%$ \\
past year (274) & & $1.03(0-20)$ \\
Days of deliberate self harm (to carers & Mean (range) & $13.07(0-365)$ \\
knowledge) in past year (268) & & \\
Days involving attempted suicide (to carers & Mean (range) & 2.69 (0-365) \\
knowledge) in past year (272) & & \\
\hline Table 2. Demographic characteristics of the relative with BPD cared for in this study.
\end{tabular}

Table 2. Demographic characteristics of the relative with BPD cared for in this study.

Numbers in parentheses indicate sample size. 


\begin{tabular}{lccccc}
\hline \multicolumn{1}{c}{ Measure } & N & Mean & Standard Deviation & Median & Range \\
\hline BAS & 264 & 56.67 & 10.24 & 58 & $19-75$ \\
MHI-5 & 240 & 55.82 & 21.37 & 56 & $0-96$ \\
TFQ - Criticism & 257 & 31.12 & 5.34 & 32 & $13-40$ \\
TFQ - Emotional & 256 & 30.32 & 5.13 & 31 & $16-40$
\end{tabular}

Table 3. Scores of carers on included measures. $\mathrm{N}$ represents sample size that provided full data on the measure.

Note. BAS, Burden Assessment Scale; MHI-5, Mental Health Inventory - 5; TFQ -

Criticism, The Family Questionnaire - Criticism Subscale; TFQ - Emotional

Overinvolvement, The Family Questionnaire - Emotional Overinvolvement Subscale. 


\begin{tabular}{lllll}
\hline & BAS & MHI-5 & TFQ- Criticism & $\begin{array}{l}\text { TFQ - Emotional } \\
\text { Overinvolvement }\end{array}$ \\
\hline BAS & $1.00^{\mathrm{a}}$ & $-0.29^{* * \mathrm{~b}}$ & $0.29^{* * \mathrm{~d}}$ & $0.49^{* * \mathrm{~g}}$ \\
MHI-5 & & $1.00^{\mathrm{c}}$ & $-0.15^{* \mathrm{e}}$ & $-0.32^{* *} \mathrm{e}$ \\
TFQ - Criticism & & & $1.00^{\mathrm{f}}$ & $0.31^{* * \mathrm{~h}}$ \\
TFQ - Emotional & & & & $1.00^{\mathrm{i}}$ \\
Overinvolvement & & & & \\
\hline
\end{tabular}

Table 4. Kendall's tau-b correlation matrix of the variables.

${ }^{*} p<0.01 ;{ }^{* *} p<0.001$

${ }^{\text {a }} \mathrm{N}=264 ;{ }^{\mathrm{b}} \mathrm{N}=233 ;{ }^{\mathrm{c}} \mathrm{N}=240 ;{ }^{\mathrm{d}} \mathrm{N}=251 ;{ }^{\mathrm{e}} \mathrm{N}=237 ;{ }^{\mathrm{f}} \mathrm{N}=257 ;{ }^{\mathrm{g}} \mathrm{N}=249 ;{ }^{\mathrm{h}} \mathrm{N}=253 ;{ }^{\mathrm{i}} \mathrm{N}=256$

Note. BAS, Burden Assessment Scale; MHI-5, Mental Health Inventory - 5; TFQ -

Criticism, The Family Questionnaire - Criticism Subscale; TFQ - Emotional

Overinvolvement, The Family Questionnaire - Emotional Overinvolvement Subscale. 


\begin{tabular}{lllll}
\hline \multicolumn{1}{c}{ Measure } & $\begin{array}{c}\text { Biologically } \\
\text { related carers }\end{array}$ & $\begin{array}{c}\text { Non- } \\
\text { biologically } \\
\text { related carers }\end{array}$ & Parents & $\begin{array}{c}\text { Partners and } \\
\text { spouses }\end{array}$ \\
\hline TFQ - Criticism & $\mathrm{N}=151$ & $\mathrm{~N}=106$ & $\mathrm{~N}=103$ & $\mathrm{~N}=86$ \\
& $\mathrm{M}=31.06$ & $\mathrm{M}=31.21$ & $\mathrm{M}=30.42$ & $\mathrm{M}=31.21$ \\
& $\mathrm{SD}=5.46$ & $\mathrm{SD}=5.18$ & $\mathrm{SD}=5.59$ & $\mathrm{SD}=5.22$ \\
TFQ - Emotional & $\mathrm{N}=152$ & $\mathrm{~N}=104$ & $\mathrm{~N}=105$ & $\mathrm{~N}=84$ \\
overinvolvement & $\mathrm{M}=29.92$ & $\mathrm{M}=30.89$ & $\mathrm{M}=30.26$ & $\mathrm{M}=31.07$ \\
& $\mathrm{SD}=5.32$ & $\mathrm{SD}=4.81$ & $\mathrm{SD}=5.13$ & $\mathrm{SD}=4.72$ \\
BAS & $\mathrm{N}=155$ & $\mathrm{~N}=109$ & $\mathrm{~N}=106$ & $\mathrm{~N}=89$ \\
& $\mathrm{M}=55.56$ & $\mathrm{M}=58.24$ & $\mathrm{M}=56.32$ & $\mathrm{M}=58.43$ \\
& $\mathrm{SD}=11.16$ & $\mathrm{SD}=8.57$ & $\mathrm{SD}=10.05$ & $\mathrm{SD}=8.61$ \\
& $\mathrm{~N}=142$ & $\mathrm{~N}=98$ & $\mathrm{~N}=99$ & $\mathrm{~N}=80$ \\
& $\mathrm{M}=57.69$ & $\mathrm{M}=53.10$ & $\mathrm{M}=58.10$ & $\mathrm{M}=52.90$ \\
& $\mathrm{SD}=20.31$ & $\mathrm{SD}=22.65$ & $\mathrm{SD}=20.25$ & $\mathrm{SD}=22.34$ \\
\hline
\end{tabular}

Table 5. Scores on measures for biologically related and non-biologically related groups, and parents and partner or spouse groups. $\mathrm{N}$ represents sample size that provided full data on the measure.

Note. TFQ - Criticism, The Family Questionnaire - Criticism Subscale; TFQ - Emotional Overinvolvement, The Family Questionnaire - Emotional Overinvolvement Subscale; BAS, Burden Assessment Scale; MHI-5, Mental Health Inventory - 5. 


\section{REFERENCES}

American Psychiatric Association. (2013). Diagnostic and statistical manual of mental disorders (5th ed.). Washington, DC.

Bailey, R. C., \& Grenyer, B. F. S. (2013). Burden and support needs of carers of persons with borderline personality disorder: A systematic review. Harvard Review of Psychiatry, 21(5), 248-258. doi: 10.1097/HRP.0b013e3182a75c2c

Bailey, R. C., \& Grenyer, B. F. S. (2014). Supporting a person with personality disorder: A study of carer burden and well-being. Journal Of Personality Disorders, $e$-View Ahead of Print. doi: 10.1521/pedi_2014_28_136

Bebbington, P., \& Kuipers, L. (1994). The predictive utility of expressed emotion in schizophrenia: An aggregate analysis. Psychological Medicine, 21, 707-718. doi: 10.1017/S0033291700027860

Bourke, M., \& Grenyer, B. F. S. (2010). Psychotherapists' response to borderline personality disorder: A core conflictual relationship theme analysis. Psychotherapy Research, 20(6), 680-691. doi: 10.1080/10503307.2010.504242

Bourke, M., \& Grenyer, B. F. S. (2013). Therapists' accounts of psychotherapy process associated with treating patients with borderline personality disorder. Journal of Personality Disorders, e-View Ahead of Print. doi: 10.1521/pedi_2013_27_108

Boye, B., Munkvold, O. G., Bentsen, H., Notland, T. H., Lersbryggen, A. B., Oskarsson, K. H., . . Malt, U. F. (1998). Pattern of emotional overinvolvement in relatives of patients with schizophrenia: A stress syndrome analogue? Nordic Journal of Psychiatry, 52(6), 493-499. doi: 10.1080/08039489850139283

Butzlaff, R. L., \& Hooley, J. M. (1998). Expressed emotion and psychiatric relapse: A metaanalysis. Archives of General Psychiatry, 55(6), 547-552. doi: 10.1001/archpsyc.55.6.547

Carrà, G., Cazzullo, C. L., \& Clerici, M. (2012). The association between expressed emotion, illness severity and subjective burden of care in relatives of patients with schizophrenia: Findings from an Italian population. BMC Psychiatry, 12(140), 1-8. doi: 10.1186/1471-244X-12-140

Cuijpers, P., Smits, N., Donker, T., ten Have, M., \& de Graaf, R. (2009). Screening for mood and anxiety disorders with the five-item, the three-item, and the two-item Mental Health Inventory. Psychiatry Research, 168, 250-255. doi: 10.1016/j.psychres.2008.05.012

Distel, M. A., Trull, T. J., Derom, C. A., Thiery, E. W., Grimmer, M. A., Martin, N. G., . . Boomsma, D. I. (2008). Heritability of borderline personality disorder features is similar across three countries. Psychological Medicine, 38(9), 1219-1229. doi: 10.1017/S0033291707002024

Dossetor, D. R., Nicol, A. R., Stretch, D. D., \& Rajkhowa, S. J. (1994). A study of expressed emotion in the parental primary carers of adolescents with intellectual impairment. Journal of Intellectual Disability Research, 38(5), 487-499. doi: 10.1111/j.13652788.1994.tb00438.x

Giffin, J. (2008). Family experiences of borderline personality disorder. Australian and New Zealand Journal of Family Therapy, 29(3), 133-138. doi: 10.1375/anft.29.3.133

Goodman, M., Patil, U., Triebwasser, J., Hoffman, P., Weinstein, Z. A., \& New, A. (2011). Parental burden associated with borderline personality disorder in female offspring. Journal Of Personality Disorders, 25(1), 59-74. doi: 10.1521/pedi.2011.25.1.59

Gunderson, J., \& Lyoo, I. K. (1997). Family problems and relationships for adults with borderline personality disorder. Harvard Review of Psychiatry, 4, 272-278. doi: 10.3109/10673229709030553 
Herman, J. L., Perry, J. C., \& van der Kolk, B. A. (1989). Childhood trauma in borderline personality disorder. The American Journal of Psychiatry, 146(4), 490-495.

Herman, J. L., \& van der Kolk, B. A. (1987). Traumatic antecedents of borderline personality disorder. In B. A. van der Kolk (Ed.), Psychological trauma (pp. 111-126). Washington, DC: American Psychiatric Press.

Herpertz, S. C., Dietrich, T. M., Wenning, B., Krings, T., Erberich, S. G., Willmes, K., . . . Sass, H. (2001). Evidence of abnormal amygdala functioning in borderline personality disorder: A functional MRI study. Biological Psychiatry, 50(4), 292-298. doi: 10.1016/S0006-3223(01)01075-7

Hoffman, P. D., Buteau, E., Hooley, J. M., Fruzzetti, A. E., \& Bruce, M. L. (2003). Family members' knowledge about borderline personality disorder: Correspondence with their levels of depression, burden, distress, and expressed emotion. Family Process, 42(4), 469-478. doi: 10.1111/j.1545-5300.2003.00469.x

Hoffman, P. D., \& Hooley, J. M. (1998). Expressed emotion and the treatment of borderline personality disorder. In Session: Psychotherapy in Practice, 4(3), 39-54. doi: 10.1002/(SICI)1520-6572(199823)4:3<39::AID-SESS4>3.0.CO;2-3

Hooley, J. M., Gruber, S. A., Parker, H. A., Guillaumot, J., Rogowska, J., \& Yurgelun-Todd, D. A. (2010). Neural processing of emotional overinvolvement in borderline personality disorder. Journal of Clinical Psychiatry, 71(8), 1017-1021. doi: 10.4088/JCP.07m03465blu

Hooley, J. M., \& Hoffman, P. D. (1999). Expressed emotion and clinical outcome in borderline personality disorder. The American Journal of Psychiatry, 156(10), 15571562.

Hooley, J. M., Orley, J., \& Teasdale, J. D. (1986). Levels of expressed emotion and relapse in depressed patients. British Journal of Psychiatry, 148, 642-647. doi: 10.1192/bjp.148.6.642

Jeppesen, P., Nordentoft, M., Abel, M., Hemmingsen, R., Joergensen, P., Kassow, P., \& Resiby, N. (2000). Expressed emotion and family burden in first episode psychosis. Schizophrenia Research, 41(1), 168-169. doi: 10.1016/S0920-9964(00)90708-4

King-Casas, B., Sharp, C., Lomax-Bream, L., Lohrenz, T., Fonagy, P., \& Montague, P. R. (2008). The rupture and repair of cooperation in borderline personality disorder. Science, 321(5890), 806-810. doi: 10.1126/science.1156902

Landecker, H. (1992). The role of childhood sexual trauma in the etiology of borderline personality disorder: Considerations for diagnosis and treatment. Psychotherapy, 29(2), 234-242. doi: 10.1037/0033-3204.29.2.234

Leichsenring, F., Leibing, E., Kruse, J., New, A., \& Leweke, F. (2011). Borderline personality disorder. Lancet, 377, 74-84. doi: 10.1016/S0140-6736(10)61422-5

Lewis, K., \& Grenyer, B. F. S. (2009). Borderline personality or complex posttraumatic stress disorder? An update on the controversy. Harvard Review of Psychiatry, 17(5), 322328. doi: 10.3109/10673220903271848

Lynskey, M. T., \& Fergusson, D. M. (1997). Factors protecting against the development of adjustment difficulties in young adults exposed to childhood sexual abuse. Child Abuse \& Neglect, 21(12), 1177-1190. doi: 10.1016/S0145-2134(97)00093-8

Masterson, J., \& Rinsley, D. (1975). The borderline syndrome: the role of the mother in the genesis and psychic structure of the borderline personality. International Journal of Psychoanalysis, 56, 163-177.

Miklowitz, D. J., Goldstein, M. J., Nuechterlein, K. H., Snyder, K. S., \& Mintz, J. (1988). Family factors and the course of bipolar affective disorder. Archives of General Psychiatry, 45(3), 225-231. doi: 10.1001/archpsyc.1988.01800270033004 
National Health and Medical Research Council. (2012). Clinical practice guideline for the management of borderline personality disorder. Melbourne: National Health and Medical Research Council.

National Institute for Health and Clinical Excellence. (2009). Borderline personality disorder: Treatment and management. London: The British Psychological Society and The Royal College of Psychiatrists.

Page, A., Hooke, G., O'Brien, N., \& de Felice, N. (2006). Assessment of distress and burden in Australian private psychiatric inpatients. Australasian Psychiatry: Bulletin Of Royal Australian And New Zealand College Of Psychiatrists, 14(3), 285-290. doi: 10.1111/j.1440-1665.2006.02293.x

Pizzagalli, D. A., Sherwood, R. J., Henriques, J. B., \& Davidson, R. J. (2005). Frontal brain asymmetry and reward responsiveness: A source-localization study. Psychological Science, 16(10), 805-813. doi: 10.1111/j.1467-9280.2005.01618.x

Platt, S. (1985). Measuring the burden of psychiatric illness on the family: An evaluation of some rating scales. Psychological Medicine, 15(2), 383-393. doi: 10.1017/S0033291700023680

Project Air Strategy for Personality Disorders. (2012). Treatment guidelines for personality disorders. Wollongong: NSW Health and Illawarra Health and Medical Research Institute.

Reinhard, S. C., Gubman, G. D., Horwitz, A. V., \& Minsky, S. (1994). Burden assessment scale for families of the seriously mentally ill. Evaluation and Program Planning, 17(3), 261-269. doi: 10.1016/0149-7189(94)90004-3

Rumpf, H.-J., Meyer, C., Hapke, U., \& John, U. (2001). Screening for mental health: Validity of the MHI-5 using DSM-IV Axis I psychiatric disorders as gold standard. Psychiatry Research, 105(3), 243-253. doi: 10.1016/S0165-1781(01)00329-8

Soloff, P. H., \& Millward, J. W. (1983). Developmental histories of borderline patients. Comprehensive Psychiatry, 24(6), 574-588. doi: 10.1016/0010-440X(83)90026-3

Theunissen, M.-J., Jansen, M., \& van Gestel, A. (2011). Are mental health and binge drinking associated in Dutch adolescents? Cross-sectional public health study. BMC Research Notes, 4(1), 100. doi: 10.1186/1756-0500-4-100

Townsend, A. L., \& Franks, M. M. (1995). Binding ties: Closeness and conflict in adult children's caregiving relationships. Psychology and Aging, 10(3), 343-351. doi: 10.1037/0882-7974.10.3.343

Wiedemann, G., Rayki, O., Feinstein, E., \& Hahlweg, K. (2002). The Family Questionnaire: Development and validation of a new self-report scale for assessing expressed emotion. Psychiatry Research, 109, 265-279. doi: 10.1016/S0165-1781(02)00023-9

Zanarini, M. C., Gunderson, J., Marino, M. F., Schwartz, E. O., \& Frankenburg, F. R. (1989). Childhood experiences of borderline patients. Comprehensive Psychiatry, 30(1), 1825. doi: 10.1016/0010-440X(89)90114-4

Zanarini, M. C., Vujanovic, A. A., Parachini, E. A., Boulanger, J. L., Frankenburg, F. R., \& Hennen, J. (2003). A screening measure for BPD: The McLean Screening Instrument for Borderline Personality Disorder (MSI-BPD). Journal Of Personality Disorders, 17(6), 568-573. doi: 10.1521/pedi.17.6.568.25355 